\section{Velikovsky's theory}

SIR-In his review of Henry Bauer's Beyond Velikovsky (Nature 25 April, pp. 692-693), Owen Gingerich claims that Peter Huber has "provided evidence from Babylonian records that Venus in $1600 \mathrm{BC}$ behaved just as it did in the centuries immediately before our own era" - and therefore essentially as it does today. What Gingerich is trying to show is that Velikovsky's theory that Earth and other planets experienced orbital changes as recently as twenty-seven centuries ago must be false. The Venus or Ninsianna tablets to which Huber and Gingerich are referring record invisibilities of Venus at inferior and superior conjunctions over a number of years. But the lengths and spacings of those invisibilities are grossly incompatible with what is seen today. This fact was discussed by Velikovsky in 1950 (Worlds in Collision, pp.198-199), as evidence supporting his theories.

As far as I know, no serious investigator of Velikovsky's theories has ever "worked hard to discredit the Babylonian data", as Gingerich claims. On the contrary, Raymond C. Vaughan and $I$, in a series of publications going back to the early 1970 s, have worked to vindicate the Babylonian data. Those who want to discredit the data are precisely people like Gingerich and Huber, who have to reject about twothirds of the data. (See Kronos X:2, pp.112.) When these records are taken seriously and are analysed in terms of the orbits that they imply, one of the findings is that Earth was on an orbit whose eccentricity was at least five or six times the present value. Thus the Babylonian observations of Venus or Ninsianna strongly support Velikovsky's theory that Earth has undergone catastrophic orbital change within historical times.

State University of New York,

LYNN E. ROSE

Department of Philosophy,

Baldy Hall,

Buffalo, New York 14260, USA

\section{Price of star wars}

SiR-The primary aim of President Reagan's Strategic Defense Initiative is to attack Soviet Intercontinental Ballistic Missiles with particle-beam (or other futuristic) weapons during the boost phase. At this stage, missiles from, for instance, the major Soviet launch site at Plesetsk are likely to be near the Finnish border. A successful strike will either damage the guidance electronics or detonate the high-explosive trigger of the nuclear warhead (without necessarily causing a nuclear explosion). Either action could direct radioactive material onto Europe; the explosive action would also scatter radioactive elements into the atmosphere.

A Soviet first strike might involve some 5,000 warheads. If only 20 per cent of these, each containing about $10 \mathrm{~kg}$ of plutonium-239 (half-life $2.4 \times 10^{4} \mathrm{yr}$ ), disintegrate (without a nuclear explosion) in the Northern Hemisphere, about $10^{13}$ lethal doses (if inhaled or ingested) of radioactive material will be released about 5,000 per person in the Northern Hemisphere. Is this not a high price to pay for the President's star wars dream?

Devana, Cardinal's Green.

R. V. HARROWELL

Horseheath, Cambridge CBI 6QX, UK

\section{Sahel famine}

SIR-As a layman, I suggest that the plan by A. R. E. Sinclair and J. M. Fryxell (see Nature 5 September, p.13) for the recovery of Sahel fertility omits two essential items. First is the need for political stability and second for social approval of the proposals. In a previous major incident, the treatment of the dustbowl in the southern plains of the United States in the 1930 s, the political stability was there but social acceptance was not, and recovery was organized by agronomists and not ecologists.

Man is not forced to accept traditional solutions to his problems; his nature enables him to invent new ones.

Llangwmville,

E. Nicholl

Llanrothal,

Monmouth NP5 3QL, UK

\section{Japan's performance}

SIR-In their illuminating Commentary (Nature 316, 587; 1985) based on a comparative study of the scientific performance of major industrialized countries, Irvine, Martin and Turner repeatedly emphasize the remarkable achievements of Japan in terms of both publication and citation over the period 1973-82. I wonder whether their praise is justified. They give only the percentage increases of the share in publication and citation (40 per cent and 65 per cent respectively) and apparently base their conclusion on these numbers. The ratio of two numbers can become large for two distinct reasons; either the numerator is large or the denominator is small. The percentage increase can look unduly large for some non-intrinsic reason, for example Japanbased literature is less comprehensively surveyed in 1973 than in 1982 , or the share itself is so small that its small increase leads to a large percentage increase. For the purpose of learning whether such factors have to be remembered in accepting the conclusion, I request the authors to publish the share of individual countries either for the year 1973 or 1982 or for both.

Department of Physics,

Katuhisa Suzuki

Osaka University,

Toyonaka 560, Japan

\section{Over-exposure?}

SIR-Nature has gone too far this time - I refer to the article on volcanism in the South Pacific (Nature 316, 507-511; 1985), with 19 authors from 18 institutes. Altogether the title of the article and names and addresses of the authors occupy 50 per cent of a page, over 10 per cent of the total article. For what purpose? A cynical reviewer might suggest the intention was that the maximum number of scientists, and for that matter institutions, should get referable exposure in Nature. Nature column inches are extremely valuable and are surely designed for communicating science. Are they being subverted for selfpromotion?

Department of Molecular

and Life Sciences,

Dundee College of Technology,

Bell Street, Dundee DDI 1HG, UK

\section{PhD theses}

SIR-I am not sure whether Beverley Halstead's statement (Nature 29 August, p. 760) that "if the material is not suitable for publication, then it was not worth doing in the first place" would find favour with those who spend many years painstakingly developing a new area before it can yield publishable results. This should not, however, be a task for a PhD student, and so the requirement suggested by $\mathrm{Dr}$ Halstead for academic publication before the reward of a $\mathrm{PhD}$ seems reasonable.

But were this to be insisted on, some measures would have to be taken to ensure that students were given projects that stood a reasonable chance of success given sufficient talent and enthusiasm on the part of the student. The departments of our universities are full of postgraduates working under inadequate supervision on projects that have little hope of success. Supervisors too often seem to regard the arrival of a student as an opportunity to move into a new field with which they themselves are not familiar and to which they would not devote their own efforts. The end result is frequently a poor thesis, cobbled together from bits and pieces, or, worse, a failed and disillusioned student.

A few years ago, the Science and Engineering Research Council published a small booklet called $A$ Guide to Good Supervisory Practice. Its contents were aimed at both supervisor and student. It contained a number of suggestions which, if thoughtfully applied, would help to ease the labour pains involved in the production of that troublesome yet coveted child, the PhD thesis. It is sad that, all too often, one or both of the involved parties have less interest in the birth than might have been expected given the difficulties in the gestation.

Department of Biochemistry,

University of Bristol, Medical School,

University Walk, Bristol BS8 1TD, UK 